\title{
Impact of Sectoral Decompositions of Electricity Consumption On Economic Growth In India: Evidence From SVAR Framework
}

Debi Prasad Bal ( $\sim$ debiprasad.bal@gmail.com )

Birla Global University

\section{Sujit Kumar Patra}

GITAM Deemed to be University

\section{Seba Mohanty}

C. V. Raman Global University

\section{Research Article}

Keywords: Electricity Consumption, Economic Growth, TFP, DEA, Commercial and Structural VAR

Posted Date: December 28th, 2021

DOl: https://doi.org/10.21203/rs.3.rs-1118041/v1

License: (c) (i) This work is licensed under a Creative Commons Attribution 4.0 International License.

Read Full License

Version of Record: A version of this preprint was published at Environmental Science and Pollution Research on March 4th, 2022. See the published version at https://doi.org/10.1007/s11356-022-19352-2. 


\title{
Impact of Sectoral Decompositions of Electricity Consumption on
}

\section{Economic Growth in India: Evidence from SVAR Framework}

\author{
Debi Prasad Bal ${ }^{1}$, Sujit Kumar Patra ${ }^{2} \&$ Seba Mohanty $^{3}$
}

\begin{abstract}
This study examine the effects of electricity consumption from different sectors such as agricultural, commercial, domestic, Industrial (HV), Industrial (LV-MV) and Miscellaneous sector on economic growth over the period of 1981-2019 in case of India. We used SVAR framework and concluded that the consumption of electricity from agriculture sector has a negative impact on economic growth. Whereas, the Industrial (HV and MV-LV) and commercial electricity consumption have positive impact on economic growth. Similarly, electricity consumption by the domestic sector has less positive effect on economic growth. Further, we computed the total factor productivity growth (TFP) by using DEA method and show the effects of sector wise electricity consumption on TFP as the robustness of our analysis. We obtain similar kind of results. From the policy perceptive, the study suggests that government must speed up the construction of a power grid to improve the availability of electricity for achieving higher rate of economic growth.
\end{abstract}

Keywords: Electricity Consumption; Economic Growth; TFP; DEA; Commercial and Structural VAR

\footnotetext{
${ }^{1}$ Assistant Professor of Economics, Birla School of Social Sciences \& Humanities, Birla Global University, Bhubaneswar, Ph No-+91-8790945328, E-mail-debiprasad.bal@gmail.com

${ }^{2}$ Associate Professor, GITAM Institute of Management, GITAM Deemed to be University, Visskhapatnam, Ph No+91-9583312434, E-mail- spatra@ gitam.edu

${ }^{3}$ Assistant Professor, Department of Management, C. V. Raman Global University, Bhubaneswar, Ph No- +919800166704, E-mail-mohanty.seba@gmail.com
} 


\section{Introduction}

In last 20 years, multiple research are carried out to examine the possible linkage of energy usage and economic development. It is being observed that the world's energy demand is continuously rising (Suganthi et al., 2012). The exponential growth of the human population, migration and urbanisation is the primary driver of global energy consumption growth. (Apergis et al. (2011), Ouedraogo et al (2013) and Chen et al. (2007, 2017)). Electricity power is a prominent source of secondary Renewable energy that is obtained through the conversion of primary energy. It is a form of crucial energy resource that is directly related to the country's economy and it's citizen's development and well-being. Electricity is considered as a critical contributor in the advancement of economic and social development. Raising electrical power usage, particularly in the development of industrial sector, is a vital indicator of a country's increasing per capita income and economic well being. The rapid development of India's economy has resulted in a substantial increase in electricity demand. Electricity production and consumption have a direct impact on economic growth and development quality. (Salahuddin and Alam (2016); Bhattacharya et al. (2016); Rafindadi and Ozturk (2016); Adedokun (2015); Sarwar et al. (2017); Cowan et al. (2014); Hossain (2012); Omri (2014)) studies the possible association between the use of electricity and economic development activity with respect to four dimensions of (conservative, growth, neutrality, and feedback). Since the economic reform of 1990, Industrialization, Urbanisation, and agricultural modernisation have all contributed to India's rapid economic development. The electricity consumption in India has witnessed a high surge from the year 2000. The number of residences having access to electric power has spiked dramatically from almost 55 per cent in 2001 to excess of 80 per cent in 2017. In 2014, an electrified Indian family used roughly 90 kilowatt-hours $(\mathrm{kWh})$ per month, which was adequate to support four ceiling fans, four tube lights, a small refrigerator, a television, and smaller kitchen equipment during typical Indian consumption efficiency levels, and hours. It accounts for three-quarters of Chinese monthly household consumption, a tenth of US consumption, and a third of global consumption. In terms of som total of power consumption in 2018-19, the industry sector accounted for the highest proportion (42.0\%), followed by the household (24.0\%), agriculture (18.0\%), and commercial sectors (10 per cent). From 2009-10 to 2018-19, 
energy consumption in the industrial and home sectors grew substantially quicker than in other

52 sectors, with CAGRs of 7.4\% and 6.7\%, respectively. (Energy Statistics, 2019).

53 Our Investigation differs from the current literature in three ways. First, we have segregated the 54 electricity consumption of India over different sectors viz. agricultural, commercial, domestic, Industrial (both HV and LV - MV) and miscellaneous sectors to study the effect of each sector rather than the aggregate effect. Second, we have used economic freedom and urbanisation as the control variables, which are lacking in the previous studies. These factors have an impact on energy consumption and economic growth in developing countries like India. Finally, we assessed total factor productivity (TFP) growth and proved the impact of sector-specific power consumption on total factor productivity (TFP) to ensure the validity of our findings. final section discusses the conclusions of the study.

\section{Literature Review}

Since the landmark research, of Kraft and Kraft (1978) and Acaravci et al. (2015) shows, the cause and effect association between economic activity and electricity use and reveals that energy consumption promotes economic growth in a one-way fashion. Salahuddin and Alam (2016) examined OECD countries' panel data on electricity use, information technology, and economic activity from 1985 to 2012 using the Dumitrescu-Hurlin causality test and the pooled mean group regression technique. It is determined that the higher usage of electricity stimulates development and economic growth. Masuduzzaman (2012) studied the possible association between financial investment, economic development, and electric power usage in Bangladesh using causality analysis and co-integration. The variables were discovered to have a long-term relationship. Electricity is considered to be the Granger cause of the growth of an economy. Apergis and Payne (2010); Apergis and Payne (2011)) support the feedback and conservative 
(2014) studies the linkage between economic activity and use of electricity in 21 growing countries, along with India, using Granger causality and panel co-integration analyses. Panel cointegration and Granger techniques were applied to a set of data for a period of four decades from 1970-2011. They observed that electric power usage effects economic growth positively in all of the nations studied and it is noticed that there exists a bidirectional causality between economic activity and energy use. Ocal and Aslan (2013) The Toda-Yamamoto causality tests were used to validate the conservation theory in Turkey from 1990 to 2010.Rafindadi and Ozturk (2016) investigated how trade and commerce influence Japan's electricity use. Their studies also revealed a causal feedback impact between exports, use of electricity, imports, economic activity, financial expansion, and capital formation. Despite much evidence supporting a unidirectional or bidirectional linkage among renewable energy deployment, and economic growth or any other contradictory research arguement that no such relationship exists. In this case, Cowan et al. (2014) Using long-term panel data, researchers investigated the link between economic activity, electric power use, and carbon emissions for the BRICS countries from 1990 to 2010, In the cases of India, Brazil, and China, the neutrality hypothesis was validated, as was the conservation hypothesis for South Africa and feedback hypothesis for Russia was also validated. However, For the countries like Bangladesh, India, and Pakistan, from the year 1976 to 2009, Hossain (2012) was unable to determine a causal association between electric power use, exports , remittances and economic activity. In another study, Joyeux and Ripple (2007) found no co-integration between household energy usage and GDP using panel data for some of the East Indian Ocean countries. For the period 1971-2007, Hossain and Saeki (2011) used a VECM model with two important variables on data from Nepal, India, Bangladesh, Sri Lanka, Pakistan, and Iran. They identified a co-integration vector in support of the hypothesid for economic growth with the use of electricity in Bangladesh, as well as in India, Pakistan, and Nepal, there is support for electricity-driven economic growth, as well as the conservative hypothesis' application. Other studies in India demonstrate the impact of energy use on other economic activities. By using a model with two variables spanning the years 1950-1996, Ghosh (2002) revealed that the Dimensions were not co-integrated and that economic growth was influenced by electricity use, rather than the other way around. Kumari and Sharma (2016) found similar results between 1974 and 2014 using the same methods. In another study, Ghosh (2009) used a multivariate model to observe the association among electric power utilization and 
111 development in economic growth, Adding employment as a variable and substituting supply of 112 electricity for variable electric power use. There was evidence of a co-integration link and one113 way Granger causation from electricity supply to employment and GDP. Using a bivariate VAR 114 model, Murray and Nan (1994) and Chen et al. (2007) concluded that India's economic 115 development activity and electricity use were not co-integrated. Similarly, Abbas and 116 Choudhury (2013) advocated for India's neutrality hypothesis. They concluded that, in order to 117 ensure environmental sustainability, India's electricity consumption might be cut without hurting 118 the country's economic growth. causality on different state-level panel data to discover a two way association among economic activity and electricity use in India. Similarly, Ahmad et al. (2014) explained the presence of cointegration among economic activity and electricity use, which forces each other, using the ARDL model.

\section{Data Sources and Methodology}

\subsection{Data Sources}

126

127 128

129 130 131

The research uses the yearly data from 1981 to 2019 to examine the association between sectorwise electricity consumption and economic growth, i.e. agricultural, commercial, domestic, Industrial (HV), Industrial (LV-MV) and Miscellaneous sectors of India. The electricity consumption variables are consumed in the agricultural, commercial, domestic, Industrial (HV), Industrial (LV-MV) and Miscellaneous sectors. The sector-wise data are gathered from the Foundation database of Economic \& Political Weekly. The degree of economic freedom and urbanisation are used as control variables in the model. The data on the degree of economic freedom and urbanisation are gathered from the World Bank Database's world Development Indicator. Finally, Total Factor Productivity data is also used as an output variable to conduct a robustness check of the results derived from GDP using an output variable. Data at constant prices (2011US\$) on real GDP is taken as a proxy for economic growth, constant prices (2011US\$) real capital stock is taken, total primary energy consumption and labour force are used to estimate the total factor productivity growth. Real capital stock statistics and real GDP are sourced from the database of Penn World (PWT9.0), while data about the labour force is 
140 sourced from the Indicators of World Bank's World Development reports and the database of 141 UNCTAD. Total primary consumption of energy data is gathered from the repository of US 142 (EIA) Energy Information Administration, and data is represented in Quadratic Btu Units.

144 We have used the Structural VAR to observe the short-run associations between sectoral 145 decomposition of electricity consumtipon on economic growth in India. The SVAR framework is 146 explained as followes.

\subsubsection{SVAR Framework}

148 We have used the structural VAR approach model to investigate the relationship between 149 electricity consumption and economic growth in India. The VAR (p) model is written as 150 follows:

$$
Y_{t}=\beta^{*} X_{t}^{\prime}+\mu_{t}^{\prime}
$$

152 Where, $\mathrm{Y}_{\mathrm{t}}$ is a $(4 \times 1)$ vector comprising of the four endogenous variables i.e. economic freedom , 153 urbanisation, electricity consumption, and economic growth. $\mathrm{X}_{\mathrm{t}}$ is the lagged of the endogenous 154 variables. $\mu_{t}^{\prime}$ is $(4 \times 1)$ vectors of residuals. The unrestricted VAR cannot able to detect the shock 155 of one variable to other variables therefore we have used the structural VAR (SVAR) model into 156 our analysis. We represent the SVAR Model as follows:

$$
A e_{t}=B \mu_{t}
$$

where, $e_{t}$ and $\mu_{t}$ are vectors of residuals derived from reduced VAR and structural shocks, 159 respectively, $\mathrm{A}$ and $\mathrm{B}$ are $\mathrm{K}^{\text {th }}$ matrices that define the linear relationship between VAR residuals 160 and structural shocks. By following the theoretical relationship among the variable we have 161 given the restriction and the model is as follows.

$$
\left[\begin{array}{cccc}
1 & 0 & a_{Y}^{U R} & 0 \\
0 & 1 & 0 & 0 \\
0 & a_{U R}^{E C} & 1 & 0 \\
0 & 0 & a_{E F}^{U R} & 1
\end{array}\right]\left[\begin{array}{c}
e_{t}^{Y} \\
e_{t}^{E C} \\
e_{t}^{U R} \\
e_{t}^{E F}
\end{array}\right]=\left[\begin{array}{cccc}
1 & b_{Y}^{E C} & 0 & b_{Y}^{E F} \\
0 & 1 & b_{E C}^{U R} & 0 \\
0 & 0 & 1 & 0 \\
b_{E F}^{Y} & 0 & 0 & 1
\end{array}\right]\left[\begin{array}{c}
\mu_{t}^{Y} \\
\mu_{t}^{E C} \\
\mu_{t}^{U R} \\
\mu_{t}^{E F}
\end{array}\right]
$$


163 Where the coefficients $a_{Y}^{U R}$ are the outcome of economic growth (Y) because of unrealised 164 disturbance in form of rapid Urbanisation (UR), $a_{U R}^{E C}$ is the response urbanisation (UR) due to unexpected shock in electricity consumption (EC), $a_{E F}^{U R}$ is the response of urbanisation due to unexpected shock in economic freedom. In the same way, the coefficient $b_{E C}^{U R}$ is the result of 167 electricity consumption (EC) due to unrealised disturbance in Urbanisation (UR), $b_{Y}^{E C}$ is the 168 outcome of economic growth(Y) due to unexpected spike in electricity usage (EC), $b_{E F}^{Y}$ is the 169 result of economic growth (Y) due to unexpected shock in economic freedom and $b_{Y}^{E F}$ Economic 170 freedom's reaction to an unexpected shock in economic growth. The coefficientse $e_{t}^{Y}, e_{t}^{E C}$, $171 e_{t}^{U R}, e_{t}^{E F}$ and $\mu_{t}^{Y}, \mu_{t}^{E C}, \mu_{t}^{U R}, \mu_{t}^{E F}$ are the residuals from the corresponding equations in the reduced 172 form VAR and structural disturbance term, respectively.

\section{Results and Discussions}

174 Before running the structural VAR model in time series analysis, the variables must be checked 175 for stationary. Since the assumptions of SVAR approach allows estimation of a co-integrating 176 vector with I(1) time series so, it is vital to exclude the possibility that any of the time series are $177 \mathrm{I}(0)$ or $\mathrm{I}(2)$. In order to be sure that the analyses do not provide any spurious results. So, the 178 regressors can be $\mathrm{I}(1)$, but no varibales should be $\mathrm{I}(2)$ or $\mathrm{I}(0)$. Using annual data from 1981 to 179 2019, a structural VAR model is applied to examine the empirical link among growth and 180 electricity usage. The unit root (Augmented Dickey Fuller, 1979) test is used to confirm that the 181 variables are stationary at first difference form. The results are presented in table-1.

182 At the level and first difference with intercept and trend, unit root tests were estimated. As 183 recommended by Schwarz, the lag selection was done using the Schwarz information criterion 184 (Pesaran and Shin, 1997). Table 1 shows the results of the ADF and PP unit root tests, which show that all of the variables at the level are non-stationary at first but become stationary after 186 the first difference at the $1 \%$ level of significance. The ADF results are confirmed by the PP 187 Test, as shown in Table-1. A summary of the PP Tests and ADF is given in Table-1, confirming 188 that none of the variables is either $\mathrm{I}(2)$ or $\mathrm{I}(0)$, so the structural VAR framework can be 189 estimated. 
In the next step, the structural VAR model is estimated. To investigate the short-run dynamics between the predictors. The outcomes of the model are shown in Tables 2 and 3. Table 2 shows that the coefficient of the outcome of economic growth because of the structural shock of electricity usage in the farming sector is significant statistically, which explains that $1 \%$ of structural shock of electricity consumption in the agricultural sector accounts to a decrease in economic growth by $0.34 \%$. In contrast, the outcome of economic growth and developmennt due to the structural shock of electricity consumption in the other sectors such as (Commercial, Domestic, industrial (HV) and Industrial (LV-MV)) are statistically significant and affects positively to the economic growth. This represents that a $1 \%$ of structural shock of electricity consumption in Commercial, Domestic, industrial (HV) and Industrial (LV-MV) leads to a $0.47 \%, 0.021 \%, 0.57 \%$ and $0.62 \%$ rise in economic growthand development by the electricity usage in corresponding sectors respectively. The other structural coefficients like the response of economic freedom due to economic growth, the response of urbanisation due to growth and the response of growth due to economic freedom exhibit a positive short relationship between them.

The economic consequences of the structural shock in electricity usage are listed below. First, the statistically significant relationships clearly highlights of a possiblity that there is a short-run association among electricity usage (except the miscellaneous sector) and growth. That means electricity usage in all the sectors except the farming sector has a positive influence on the economic growth, whereas electricity usage in the agricultural sector has a negative influence on growth.

\section{[Insert Table 1 Here]}

\section{[Insert Table 2 Here]}

This is due to a number of issues in India's agriculture industry, including a lack of water, inadequate infrastructure, land degradation, inexperienced agricultural labour, the adoption of obsolete farming practises, and rising oil/petroleum prices. The other reason could be an inefficient application of electricity in the farm sector and a lack of awareness among the farming population of India to use energy efficient-high productive farming machinery.

On the contrary, Table 2 shows that the electricity consumption by the industrial sector (both HV, MV-LV) has a substantial beneficial impact on the economy. This represents that a 
$1 \%$ of structural shock of electricity consumption in industrial (HV) and industrial (LV-MV) $0.57 \%$ and $0.62 \%$ increase in economic growth. This finding is in alignment with the widely held belief that increased energy usage leads to increased economic growth. (Abbas, Chaudhary 2013, Asafu-Adjaye, J., 2000) also finds electricity use has a considerable impact on economic growth. It can be explained in the following ways. First, The amount assigned to the industrial sector continues to expand on average, despite India's positive average growth in energy supply. Between 2000 and 2019, the industrial sector's share of electricity supply increased from 32.67 percent to 46.682 percent; however, the residential and commercial sectors' shares of electricity supply increased at a slower rate, from 21.27 percent to 24.76 percent and 6.44 to 8.24 percent, respectively. (Central Electricity Authority, 2018). Tariffs in the industrial sector have been adjusted downward, according to the Central Electricity Authority, and these rates have been sustainable in many circumstances. The high cost of electricity in the industrial sector as a result of tariff increases could possibly explain the drop in electricity use in the industry.

Similarly, the sharp rise in demand of electrcity, particularly from 1996, just the subsequent year after India joined the WTO, could be attributed to increased demand for heating, lighting, cooking, and electric appliances, as well as export-oriented industrial expansion. Another probable reason for increased growth due to industrial sector electricity consumption is the phenomenon of load shedding becoming less common after 2010, when India's electricity generation capacity was optimised to meet the economy's expanding demands. Furthermore, the industry is distinguished by the utilisation of cutting-edge, energy-efficient machinery. Therefore, it is really not surprising that with the average electricity usage in India increased, the industrial sector's contribution to GDP also increased during the period of study.

Likewise, Table 2 shows that electricity consumption by the domestic sector has a much less positive impact on economic growth. This represents that a $1 \%$ of structural shock of electricity consumption in the industrial sector responds to an increase of $0.021 \%$ in economic growth. The results reveal that rising home energy use contributed to India's economic growth over the study period, this may have something to do with the fact that India's population is growing at an alarmingly fast rate. It's worth noting that the most frequent appliances were owned by a considerable section of the population, with cooking accounting for the highest volume of per year use of total energy. In addition, domestic electrical equipment absorbs $75 \%$ 
of all electricity utilised in households. (Central Electricity Board, May 2016). As a result, income growth may appear to be a realistic component in the increase in domestic electricity demand, because higher income levels may enable the purchase and use of more appliances. McNeil and Letschert (2010) According to the report, refrigerators, air conditioners, chimneys, and washing machines account for a large portion of the increase in electricity usage in emerging countries. Therefore, when the market is saturated due to the fact that the entire population possesses these enormous appliances, The demand for electricity savings from increasing the efficiency of these large appliances is growing. In this respect, higher income makes it easier to buy energy appliances because it is based on financial ability.

The growth due to increased domestic electricity consumption may also be attributed to some other underlying causes. This could be explained by rising urbanisation and changing lifestyles. Gupta (2018) adds to this by stating that urban lifestyles in emerging countries are getting more energy-intensive. Similarly, Karanfil and Li (2015) found that, with the exception of high-income nations, urbanisation is a significant influence in power use at all income levels, with urbanisation in upper-middle-income countries like India, being the most major driver of electricity use (World Bank, 2018). According to the World Bank statistics, around 34\% of the Indian citizens lived in urban areas in 2018, up from $25 \%$ in 1995 . Nonetheless, the residential sector's increased electricity demand can be linked to the government's refusal to raise price rates for domestic supply of electricity, which is utilised in homes. (Central Electricity Authority, 2016). The elimination of these subsidies in the household sector will make energy use more price sensitive, potentially changing the current relationship between residential electricity consumption and growth.

As evident from Table 2, electricity consumption by the commercial sector has a considerable positive effect on growth. This means that a $1 \%$ increase in electricity usage in the commercial sector boosts GDP growth by 0.47 percent. The findings suggest that during the study period, economic growth increased and it can to contributed by increased commercial electricity usage, This may have something to do with the fact that the commercial sector is developing at a high rate in India. This increase can be attributed to the development in the tourism, banking, retail, education and many other service sectors. The tourism industry has 
shown outstanding growth over the study period, due to which it has contributed significantly to GDP growth. A similar trend has also been observed for the hospitality sector.

Similarly, the un-structural shock of urbanization on growth shows statistical significance except for Industrial (HV) and miscellaneous sectors. In all the other sectors, the coefficient is statistically significant, which indicates that the response of growth due to electricity usage is increasing in all the sectors except in the case of home or domestic sector is positive. This represents that a $1 \%$ of structural shock of urbanization leads to a $0.66 \%, 0.47 \%$, and $0.1 .33 \%$ increase in GDP growth in agricultural, commercial industries (LV-MV), respectively.

In the next step, we estimate the impulse response function. The results are presented in Figure 1. The results show the impact of a shock in electricity consumption in the agricultural sector on GDP growth and is presented in Figure 1 (a). Over the first to ten years, the agricultural electricity demand shock has statistically significant and negative effects on economic growth. The impact of a shock in electric power consumption on economic development is depicted in Figure 1 (b).

\section{[Insert Figure 1(a) to 1(e) Here]}

From the first to the tenth years, the shock in commercial electricity use has a statistically favourable impact on GDP growth rate, with the highest effect of shock during the third and fourth years, after which the effect of sock begins to reduce gradually. Figure 1 (c) highlights the effect of shock in domestic electricity consumption on GDP growth. This shows that the shock in domestic electricity consumption has a statistically positive impact on the GDP growth rate from the first to tenth years. Finally, Figures 1(d) and 1(e) show that the significant positive effects on economic growth are observed due to the shock of industrial electricity consumption (both HV and LV-MV).

\subsubsection{Robustness checking}

In order to obtain evidence of the robustness of our results, we calculate the total productivity growth (TFP) by using the DEA method. Moreover, the TFP growth index was constructed using the Malmquist index and was used as the output variable to examine the robustness of the results obtained by using the GDP growth as the output variable. The TFP 
growth index constructed uses not only labour and capital but total primary energy consumption as a third dimension to include the effects of energy consumption. This aspect was not used before in studying the behavior of electrifying consumption with growth variables. In several sectors, the relationship between TFP growth and electricity consumption is established using economic freedom and urbanisation as a robustness check for the established linkage between electricity consumption and economic growth in various sectors. Our results are consistent and are presented in table-3.

Table 3 shows that the coefficient of the response of TFP growth due to the structural shock of electricity consumption in the agricultural sector is statistically significant, which indicates that $1 \%$ of structural shock of electricity usage in the farm sector leads to a fall in TFP growth by $0.031 \%$. In contrast, the response of TFP growth due to the structural shock of electricity consumption in the other sectors are statistically significant; the electricity consumption in these sectors affects the TFP growth positively. This represents that a $1 \%$ of structural shock of electricity usage in commercial industrial (HV), Industrial (LV-MV), and miscellaneous sectors lead to a $0.027 \%, 0.46 \%, 0.115 \%, 0.1771 \%$, and $0.15 \%$ increase in TFP growth by the electricity consumption in corresponding sectors respectively.

\section{[Insert Table 3 Here]}

Other structural coefficients, such as economic freedom's response to TFP growth, urbanization's response to TFP growth, and TFP growth's response to economic liberty, have a short positive relationship. Similarly, the unstructured shock of urbanization on growth shows statistical significance except for Industrial (HV) and miscellaneous sectors. In all the other sectors, the coefficient is statistically significant, which indicates that the response of growth due to electricity usage in all the arenas except the domestic sector is positive. This means that a $1 \%$ urbanization structural shock leads to 0.17 percent, 0.077 percent, and 0.52 percent GDP growth in agricultural, commercial, and manufacturing industries (LV-MV), respectively.

\section{Conclusion and Policy Implications}

During the period 1981-2019, this study analyzed empirically the linkage between electricity usage in several sectors of India, including agriculture, home, commercial, industrial (HV), industrial (LV-MV), and miscellaneous sectors, and GDP growth. For each sector, various 
variables linked to electricity usage are proposed. Along with these variables, economic freedom and urbanisation were used as instrumental variables to construct the variable.

Economic growth, electricity consumption, urbanisation, and economic freedom have all been included as independent variables in a multivariate time series model. Two unit root tests were performed to determine the sequence of integration for every series included in the model to ensure consistency of results. The results of the PP test support ADF's conclusions that all variables, including electricity consumption, are non-stationary at the level but become stationary at the first difference. The findings of this study were based on empirical evidence. Following that, structural VAR was used to see if there was a short-run link between the variables. The results show the coefficient of the response of a variable due to the structural shock of another variable. We observed that the coefficient of the outcome of economic growth due to the structural shock of electricity consumption in the agricultural sector is statistically significant, which indicates that $1 \%$ of structural shock of electricity usage in the farm sector accounts to a fall in growth of economy by $0.34 \%$. In contrast, though the coefficient of the outcome of economic growth due to the structural shock of electricity consumption in the other sectors is statistically significant, the electricity consumption in these sectors affects the economic growth positively. Other structural coefficients, such as economic freedom's response to growth, urbanization's response to growth, and growth's response to economic freedom, have a short positive relationship. It revealed that economic growth, electricity consumption, urbanisation and economic freedom are significantly related among themselves. In India, population increase has a considerable impact on overall electricity consumption. Similarly, economic freedom has a significant impact on electricity consumption, which could be explained by the fact that countries with more economic freedom have stronger economies, with higher GDP per capita, which will eventually lead to increased electricity consumption to meet the increased demand to boost economic growth. From the policy perceptive, the study suggests in the following lines. First, in a big country like India, with diversity in all aspects of demography, there are significant variations in development from one corner to another from east to west or north to south of the country and from urban areas to rural areas. Similarly, according on income levels, areas can be divided into four groups. We must accelerate the installation of a power infrastructure in low- and middle-income areas to boost development. Simultaneously, we must 
work to make the rural power grid and electricity prices equal to those in cities. Second, urbanisation will have a significant impact on increased electricity demand. To accommodate an increase in the urbanized population, the Indian government must consider increasing electricity power-producing capacity. The use of electrically operated appliances by city dwellers has a substantial impact on total electricity consumption. It would be critical to implement tax cuts and customs reductions for eco-friendly energy appliances and a restriction on importing inefficient electrical equipment that unnecessarily increases the use of electricity but is cheaper. Third, policymakers must recognize that promoting agriculture programs and drawing greater industrial investments to India will significantly increase electricity demand. Finally, Electricity power construction must be incorporated into core public service construction to improve the availability of electricity for low-income communities and to improve development.

Ethical Approval: we declear that the study is original in nature and followed all ethical aspects. Consent to Participate: We declare that this manuscript is original, has not been published before and is not currently being considered for publication elsewhere. We confirm that the manuscript has been read and approved by all named authors and that there are no other persons who satisfied the criteria for authorship but are not listed. We further confirm that the order of authors listed in the manuscript has been approved by all of us.

Consent to Publish: The authors hereby given the consent to the manuscript named above in all forms to publish in this estmeed journal.

Authors Contributions: Debi Prasad Bal has developed the idea, has done the econometrics analysis, written the methodology and results section. Sujit Patra has written the introduction section, interpreted the results and overall correction of the manuscript. Seba Mohanty has collected all the data, has written the review of literature, conclusions and references.

Funding: The authors have not received any funding to developed this research paper from any agency.

Competing Interests: We declare that this manuscript has neither published nor submitted elsewhere for publication. We further declare that there is no conflict of interest related to this manuscript.

Availability of data and materials: The data and other material will be share as per the request. 


\section{References}

396 Abbas, F. and Choudhury, N., 2013. Electricity consumption-economic growth nexus: an 397 aggregated and disaggregated causality analysis in India and Pakistan. Journal of Policy 398 Modeling 35, 538-553.

399 Acaravci, A., Erdogan, S. and Akalin, G., 2015. The electricity consumption, real income, trade 400 openness and foreign direct investment: The empirical evidence from Turkey. International 401 Journal of Energy Economics and Policy 5, 4, 1050-1057.

402 Adedokun A., 2015. Can electricity consumption be useful in predicting Nigerian economic 403 growth? Evidence from error correction model, OPEC Energy review

404 Ahmad, W., Nain, M.Z. and Kamaiah, B., 2014. On the role of the trend and cyclical 405 components in electricity consumption and India's economic growth: a co-integration and 406 cofeature approach. OPEC Energy Review 38, 1, 107-126.

407 Apergis N, Payne JE. Renewable and non-renewable electricity consumption- growth nexus: 408 evidence from emerging market economies. Applied Energy 2011; 88:5226-30.

409 Apergis, Nicholas and Payne, James, (2010), Renewable energy consumption and economic 410 growth: Evidence from a panel of OECD countries, Energy Policy, 38, issue 1, p. 656-660,

411 Renewable and non-renewable energy consumptiongrowth nexus: Evidence from a panel error 412 correction model, Energy Economics, 34, issue 3, p. 733- 738.

413 Asafu-Adjaye, John, (2000), The relationship between energy consumption, energy prices and 414 economic growth: time series evidence from Asian developing countries, Energy Economics, 22, 415 issue 6, p. 615-625, https://EconPapers.repec.org/RePEc:eee:eneeco:v:22:y:2000:i:6:p:615-625.

416 Bhattacharya, M., Paramati, S.R., Ozturk, I. and Bhattacharya, S., 2016. The effect of renewable 417 energy consumption on economic growth: evidence from top 38 countries. Applied Energy 162, $418 \quad 733-741$. 
419 Chen S-T, Kuo H-I, Chen C-C. The relationship between GDP and electricity consumption in 10 420 Asian countries. Energy Policy 2007;35:2611-21.

421 Cowan, Wendy \& Chang, Tsangyao \& Inglesi-Lotz, Roula \& Gupta, Rangan. (2014). The nexus 422 of electricity consumption, economic growth and CO2 emissions in the BRICS countries. Energy 423 Policy. 66. 10.1016/j.enpol.2013.10.081.

424 Dickey, D. \& Fuller, Wayne. (1979). Distribution of the Estimators for Autoregressive Time 425 Series With a Unit Root. JASA. Journal of the American Statistical Association. 74. $426 \quad 10.2307 / 2286348$.

427 Energy Statistics. (2019). Central Statistics office, Ministry of Statistics and Programme 428 Implementation, Government of India. www.mospi.gov.in

429 Ghosh, Sajal. (2002). Electricity consumption and economic growth in India. Energy Policy. 30. 430 125-129. 10.1016/S0301-4215(01)00078-7.

431 Ghosh, S., 2009. Electricity supply, employment and real GDP in India: evidence from co432 integration and Granger-causality tests. Energy Policy 37, 2926-2929.

433 Gupta, M.D. Impact of Lifestyle Pattern on Energy Consumption and Carbon Emissions - A 434 View from India. Available online: http://www.jeaconf.org/UploadedFiles/Document/b4ceee96435 f5bd-470a8df7- 504bd7d59cc2.pdf (accessed on 15 June 2018).

436 Hossain, Anowar \& Hossain, Mohammad. (2011). Empirical Relationship between Foreign 437 Direct Investment and Economic Output in South Asian Countries: A Study on Bangladesh, 438 Pakistan and India. International Business Research. 5. 10.5539/ibr.v5n1p9.

439 Joyeux, R., Ripple, R.D., 2007. Household energy consumption versus income and relative 440 standard of living: a panelapproach. Energy Policy 35, 50-60

441 Karanfil, F.; Li, Y. Electricity consumption and economic growth: Exploring panel-specific 442 differences. Energy Policy 2015, 82, 264-277

443 Kraft J, Kraft A (1978) On the relationship between energy and GNP. J Energy Dev 3:401-403. 
444 Kumari, A. and Sharma, A.K., 2016. Analysing the causal relations between electric power 445 consumption and economic growth in India. The Electricity Journal 29, 28-35.

446 Lee YC, Hu JL, Kao CH. Efficient saving targets of electricity and energy for regions in China. 447 Electr. Power Energy Syst. 2011;33:1211-9.

448 Masuduzzaman, M., 2012. Electricity consumption and economic growth in Bangladesh: co449 integration and causality analysis. Global Journal of Management and Business Research 12,11, $450 \quad 46-56$.

451 Mcneil, Michael \& Letschert, Virginie. (2007). Future air conditioning energy consumption in 452 developing countries and what can be done about it. Proceedings of the European Council for an 453 Energy Efficient Economy (eceee). 6. 1311-1322.

454 Murry, D., \& Nan, G. (1994). A Definition of the Gross Domestic Product - Electrification 455 Interrelationship. The Journal of Energy and Development, 19(2), 275-283. Retrieved June 20, 456 2020, from www.jstor.org/stable/24808049

457 Nasreen, S. Anwar, S. (2014). Causal relationship between trade openness, economic growth and 458 energy consumption: A panel data analysis of Asian countries. Energy Policy, 69, 82-91

459 Pesaran, M. H., Y. Shin, and R. Smith, 2001, Bounds testing approaches to the analysis of level 460 relationships. Journal of Applied Econometrics, 16, pp. 289-326.

461 Ocal, Oguz \& Aslan, Alper, 2013. "Renewable energy consumption-economic growth nexus in 462 Turkey," Renewable and Sustainable Energy Reviews, Elsevier, vol. 28(C), pages 494-499.

463 Omri, A., 2014. An international literature survey on energy-economic growth nexus: evidence 464 from country-specific studies. Renewable \& Sustainable Energy Reviews 38, 951-959.

465 Ouedraogo NS. Energy consumption and human development: evidence from a panel co466 integration and error correction model. Energy 2013;63:28-41.

467 Rafindadi, Abdulkadir. (2016). Impacts of renewable energy consumption on the German 468 economic growth: Evidence from combined co-integration test. Renewable and Sustainable 469 Energy Reviews. 75. 10.1016/j.rser.2016.11.093. 
470 Saeki, C. and M.S. Hossain (2011). Does Electricity Consumption Panel Granger Cause 471 Economic Growth in South Asia? Evidence from Bangladesh, India, Iran, Nepal, Pakistan and 472 Sri-Lanka, European Journal of Social Sciences. 25(3), 316-328

473 Salahuddin, M. and Alam, K., 2016. Information communication technology, electricity 474 consumption and economic growth in OECD countries: a panel data analysis. Electrical Power \& 475 Energy Systems 76, 185-193.

476 Sarwar, Suleman \& Chen, Wei \& Waheed, Rida. (2017). Electricity consumption, oil price and 477 economic growth: Global perspective. Renewable and Sustainable Energy Reviews. 76. 9-18. $478 \quad$ 10.1016/j.rser.2017.03.063.

479 Sayin C, Mencet MN, Ozkan B. Assessing of energy policies based on Turkish agriculture: 480 current status and some implications. Energy Policy 2005;33(18):2361-73.

481 Srivastava, S.K., 2016. Causal relationship between electricity consumption and GDP: plausible 482 explanation on previously found inconsistent conclusions for India. Theoretical Economics 483 Letters 6, 276-281

484 Suganthi L, Samuel AA. Energy models for demand forecasting - a review. Renew Sustain 485 Energy Rev 2012;16:1223-40.

486 Tiwari, A. K., 2011. "A structural VAR analysis of renewable energy consumption, real GDP 487 and CO2 emissions: Evidence from India," Economics Bulletin, AccessEcon, vol. 31(2), pages 488 1793- 1806.

489 World Bank. World Bank Data, Country Classification, Country and Lending Groups. Available 490 online: https://datahelpdesk.worldbank.org/knowledgebase/articles/906519-world-bank491 countryandlending-groups (accessed on 15 June 2018).

492 Zhanda A, Kimber HM. Benefits from a renewable energy village electrification system. Renew 493 Energy 2009;34:362-8.

494 Funding:

495 The authors declare that no funds, grants, or other support were received during the preparation 496 of this manuscript. 
Figures

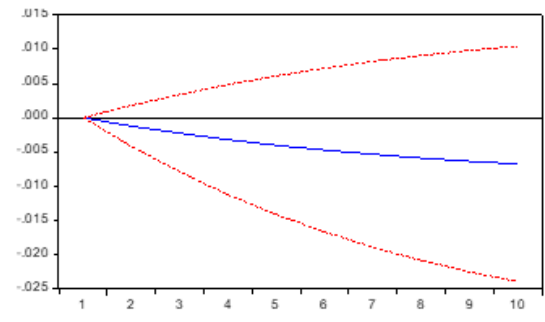

(a)

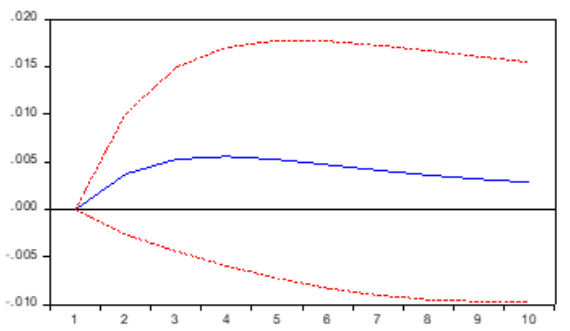

(b)

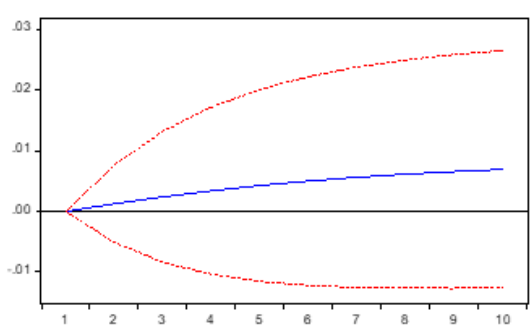

(c)

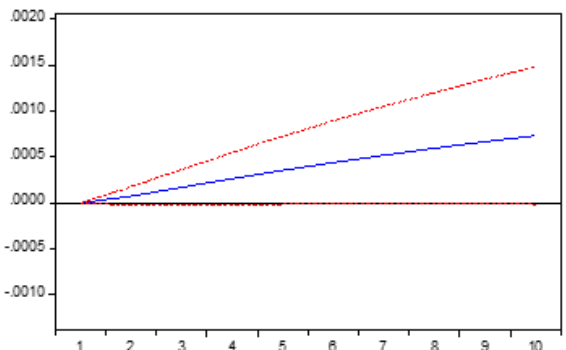

(d)

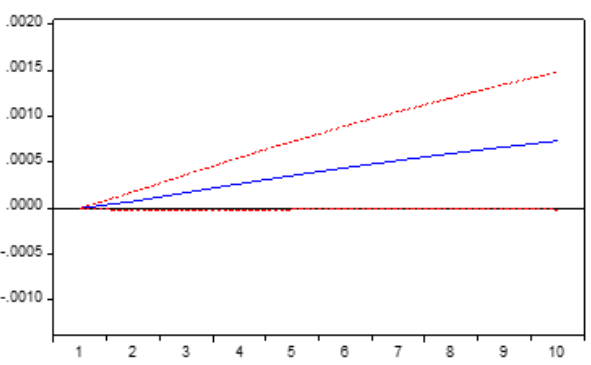

(e)

\section{Figure 1}

(a): Response of LY to LNA (b): Response of LY to LNC (c): Response of LY to LND (d): Response of LY to LNIN(HV) (e): Response of LY to LNIN(MV-LV) 